\title{
Efficacy of atypical $v$. typical antipsychotics in the treatment of early psychosis: meta-analysis
}

\author{
Nicolas A. Crossley, Miguel Constante, Philip McGuire and Paddy Power
}

\section{Background}

There is an ongoing debate about the use of atypical antipsychotics as a first-line treatment for first-episode psychosis.

\section{Aims \\ To examine the evidence base for this recommendation.}

\section{Method}

Meta-analyses of randomised controlled trials in the early phase of psychosis, looking at long-term discontinuation rates, short-term symptom changes, weight gain and extrapyramidal side-effects. Trials were identified using a combination of electronic (Cochrane Central, EMBASE, MEDLINE and PsycINFO) and manual searches.

\section{Results}

Fifteen randomised controlled trials with a total of 2522 participants were included. No significant differences between atypical and typical drugs were found for discontinuation rates (odds ratio $(\mathrm{OR})=0.7,95 \% \mathrm{Cl} 0.4$ to 1.2 ) or effect on symptoms (standardised mean difference $(\mathrm{SMD})=-0.1,95 \% \mathrm{Cl}-0.2$ to 0.02 ). Participants on atypical antipsychotics gained $2.1 \mathrm{~kg}(95 \% \mathrm{Cl} 0.1$ to 4.1$)$ more weight than those on typicals, whereas those on typicals experienced more extrapyramidal side-effects $(\mathrm{SMD}=-0.4$, $95 \% \mathrm{Cl}-0.5$ to -0.2$)$.

\section{Conclusions}

There was no evidence for differences in efficacy between atypical and typical antipsychotics, but there was a clear difference in the side-effect profile.

\section{Declaration of interest} None.
Over the past decade, atypical (or second-generation) antipsychotics have been increasingly used in the treatment of schizophrenia in preference to 'conventional' typical (first-generation) drugs. However, meta-analyses of clinical trials in participants with chronic schizophrenia have suggested a limited advantage of the newer agents in terms of efficacy ${ }^{1-4}$ and two recent large trials failed to find a difference between these two classes of antipsychotics. ${ }^{5,6}$ Furthermore, economic analyses have raised doubts about the cost-effectiveness of the newer drugs. ${ }^{7,8}$ Cost is an important factor for low- and middle- income countries, particularly if, as suggested by a previous meta-analysis, ${ }^{9}$ the cost of treatment could partly explain the inverse association between longer duration of untreated psychosis and per capita income. In this context, it has been suggested that typical antipsychotics are as useful as atypicals in the treatment of schizophrenia. ${ }^{10}$

Individuals presenting with a first episode of schizophrenia differ from those in whom the disorder is well established in that a higher proportion show a good symptomatic response. ${ }^{11}$ Moreover, the dose of antipsychotics required to achieve symptomatic remission is usually lower than in individuals with chronic schizoprhenia, ${ }^{12}$ and those with a first episode are more susceptible to extrapyramidal side-effects. ${ }^{13}$ Their younger age also puts them at risk of longer exposure to the potential metabolic complications of newer antipsychotics. ${ }^{14}$ Avoiding adverse effects when individuals first start treatment is particularly important as it may colour their attitude to medication and psychiatric treatment more generally thereafter. Antipsychotics with a benign side-effect profile thus offer an advantage in this phase of schizophrenia. This is particularly important considering the high rates of nonadherence to medication in this population, reported to be as high as $50 \% .{ }^{15}$ Regarding the question whether atypical or typical antipsychotics are better for this population a Cochrane metaanalysis from 2003 found that there was not enough evidence at that time to make recommendations. ${ }^{16}$

In the UK, a recent update to the National Institute for Health and Clinical Excellence (NICE) guideline has moved away from the previous recommendation of atypical antipsychotics as a first-line treatment in people presenting with a first episode of psychosis. ${ }^{17}$ We performed a meta-analysis to look at the efficacy and side-effects of atypical versus typical antipsychotics in the treatment of the early phase of psychosis.

\section{Method}

We included randomised controlled trials comparing atypical and typical antipsychotics in individuals in the early phase of psychosis. To be included in the meta-analysis, studies had to use a validated diagnostic system and explicitly define whether their participants were antipsychotic naive, experiencing a first episode of psychosis or were in the early phase of psychosis. We expected to find varying definitions of first episode and early psychosis, and therefore we accepted any definitions used and modelled the effects of the different duration of illness in the analyses. We excluded studies that recruited only participants with an affective psychosis, or individuals younger than 13 or older than 65 years of age. Studies needed to report at least one of the following outcomes: adherence with antipsychotic medication, symptom scales, weight or any validated measure of extrapyramidal side-effects.

In line with a recent long-term study, ${ }^{5}$ we selected 'discontinuation for any cause' at 12 months of the assigned antipsychotic (or when this was not reported, between 6-24 months), which includes drug efficacy and tolerance, as our primary measure of effectiveness. We also selected a measure of medication efficacy consisting of symptom scores at 12 weeks (or when this was not reported, between 6-18 weeks), as this is the time point at which a previous study showed that $90 \%$ of individuals with a first episode who responded to medication achieved symptomatic remission. ${ }^{18}$ When more than one symptom scale was reported, we chose to use the Positive and Negative Syndrome Scale (PANSS) first, then the Brief Psychiatric Rating Scale (BPRS) 
and then any other validated scale. Two major groups of sideeffects were assessed: weight gain and extrapyramidal side-effects, using the last reported observation of each study. When studies reported more than one arm of atypical or typical antipsychotics, effect sizes and variances of the different drugs were pooled together per group using number of participants as a weight factor.

Pertinent randomised controlled trials were identified using an electronic and a hand-based search. A computer-based search was performed using the following databases: MEDLINE (1966 to 20th January 2009), EMBASE (1980 to January Week 3 2009), PsycINFO (1806 to January Week 2 2009) and Cochrane CENTRAL (The Cochrane Library 2008, Issue 4). No language constraints were applied. Subject headings including Psychosis, Schizophrenia, and Atypical Antipsychotic Agent were used as well as text words such as 'first episode', 'never medicated', 'naïve' and names of atypical antipsychotics. Details of the search strategy can be found in the online supplement. Two of the authors (N.A.C. and M.C.) independently reviewed all the identified abstracts from the electronic search, selected the studies included and extracted the data. Any conflicts were discussed with a third reviewer (P.P.). References of the identified studies and published reviews on pharmacological management of first-episode psychosis were also searched. ${ }^{16,19}$ One of the authors (N.A.C.) undertook to handsearch data of published abstracts of the 3rd to 5th Conference on Early Psychosis and 8th to 14th Biennial Winter Workshop on Schizophrenia to complement the electronic search. Authors were contacted if data were missing.

As we anticipated different definitions of early psychosis or first-episode psychosis we expected to find significant clinical heterogeneity among the studies and therefore decided that using a random-effects analysis would be appropriate. ${ }^{20}$ When looking at adherence rates for antipsychotic medication, we preferred to use odds ratios instead of risk ratios in spite of their more difficult interpretation. This allowed us to avoid giving too much weight to trials with high event rates. ${ }^{21}$ For continuous variables, weighted means or standardised mean differences using Hedges' $g$ were used. The latter was used when more than one scale was reported in the outcomes. Heterogeneity was explored using $\chi^{2}$. $I^{2}$ is another measure of heterogeneity that refers to the proportion of the variance explained by the between-trial variance. Due to the easiness in the interpretation, it is also reported in this study. We used meta-regression to look at potential confounders in our summary measure. Knowing that we would find a limited amount of trials to include in each comparison, we only performed the regression if the variable being controlled for was reported in all the included studies. We used meta-regressions to look at the effects of the dose of typical antipsychotic used and the proportion of antipsychotic-naive participants included. The European First-Episode Schizophrenia Trial (EUFEST) suggested that masking status might cause a bias in discontinuation rates (e.g. unmasked clinicians might discontinue typical drugs sooner than atypicals if complications arose). ${ }^{22}$ Masking status was therefore also included in the model for discontinuation rates. For the side-effects analysis, we included the assessment point in time. Given the known difference in side-effect profiles for some atypicals, we also included in the regression the proportion of participants taking olanzapine or clozapine when looking at weight gain, and amisulpride or risperidone when looking at extrapyramidal symptoms. In order to avoid spurious results by overfitting the data (e.g. when more than one factor was reported in all the studies), we opted for a repeated univariate meta-regression rather than a multiple regression approach. Results of these meta-regressions should be considered exploratory because of the multiple comparisons performed.
Publication bias was explored using Egger's test. ${ }^{23}$ All analyses were done using STATA 10.0 running in Windows XP.

\section{Results}

Combined searches of the four databases yielded 1053 references. In total 105 articles were retrieved for further assessment from which 14 different randomised controlled trials were identified. Two further trials were identified in the manual search, one of which could not be included because of a lack of data (the trial looked at ziprasidone versus haloperidol and was published as a conference abstract). As a result, we included 15 randomised controlled trials that recruited a total of 2522 patients. Figure 1 summarises the study selection and exclusion process.

Risperidone was used in nine studies as the atypical antipsychotic, ${ }^{24-32}$ olanzapine was used in seven trials, ${ }^{13,22,27,28,32-34}$ and two studies used quetiapine ${ }^{22,35}$ and clozapine. ${ }^{27,36}$ Amisulpride and ziprasidone were used in one study. ${ }^{22}$ Twelve of the fifteen studies used haloperidol as the first-generation antipsychotic. The other three studies used chlorpromazine, ${ }^{36}$ oral zuclopenthixol ${ }^{25}$ and sulpiride. ${ }^{27}$ All but one study ${ }^{32}$ reported using low doses of typical antipsychotic, below the usually described cut-off point of $12 \mathrm{mg}$ of haloperidol or equivalent. ${ }^{1,4}$ Eight studies reported using doses lower than haloperidol $5 \mathrm{mg}$, 22,25-27,29,30,33,34, accounting for more than two-thirds of the total sample of participants treated with typical antipsychotics included in this review. Characteristics of the included trials and selected references are shown in online Table DS1.

Seven studies reported long-term data of discontinuation rates suitable for pooling, with a total of 1823 participants. Studies used different definitions of discontinuation, but most reported that participants were considered as discontinuing the drug due to

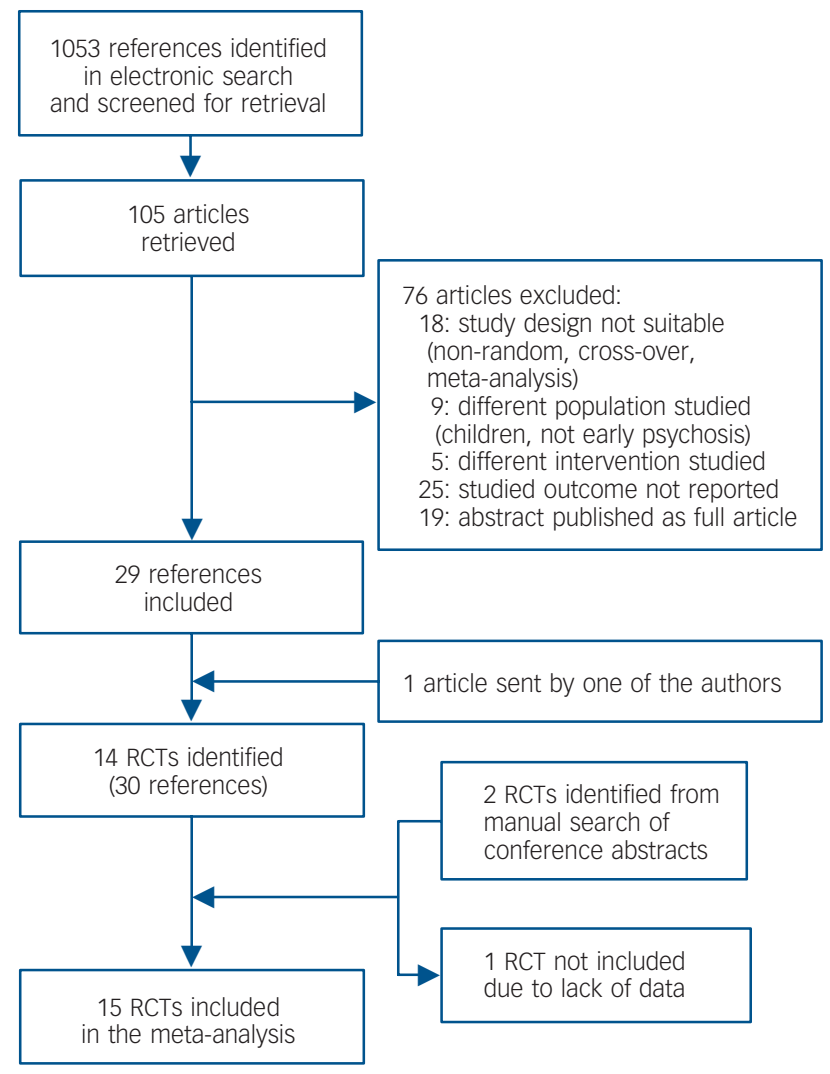

Fig. 1 Flowchart of study selection. RCT, randomised controlled study. 
side-effects or lack of response among other reasons. Only one study considered discontinuation rates as their primary outcome and explicitly defined how they measured it. ${ }^{22}$ There was a nonsignificant greater proportion of individuals prescribed atypical antipsychotics who were adherent around 1 year (Fig. 2, odds ratio $(\mathrm{OR})=0.73, P=0.22)$. On visual inspection, results appeared to differ between the different studies and not surprisingly, heterogeneity was significant as assessed with $\chi^{2}(P<0.001)$. There is an outlier finding from a small study that used quetiapine, ${ }^{35}$ and excluding this study did not change the overall result (OR=0.64, $P=0.09$ ) and had little effect on the heterogeneity observed. Masking status was reported in all seven studies. A meta-regression including masking status as the independent variable and the odds ratio of each study as the dependent variable was non-significant. In other words, masking status was not a significant moderator of the effect sizes of the studies included.

For the short-term symptomatic outcome, 12 trials were pooled with a total of 1949 participants. Most studies reported PANSS scores, although a few reported BPRS scores. Therefore standardised effect sizes were pooled. A small non-significant trend favouring atypical antipsychotics was found (s.d. $=-0.1$, $P=0.12$ ) as shown in Fig. 3. Heterogeneity was not statistically significant in the comparison according to $\chi^{2}(P=0.17)$. Since there was no significant heterogeneity found, we repeated the analysis with a fixed-effect approach as some authors have suggested, but the difference remained non-significant (s.d.= $-0.08,95 \%$ CI -0.17 to 0.02 ). We performed a meta-regression using the dose of atypical as a covariate of the effect size. There was a non-significant trend for comparisons that used higher doses of typical antipsychotics to report larger effect sizes that favoured atypicals ( $1 \mathrm{mg}$ of haloperidol equivalent accounting for standardised mean difference $(S M D)=0.02$ favouring atypicals, $P=0.09$ ).

For weight gain, a total of seven studies were pooled including 1444 participants. Pooling of the seven studies showed that individuals on atypical antipsychotics gained an extra $2.1 \mathrm{~kg}$ compared with those on typical antipsychotics $(P=0.04$, Fig. 4$)$. Heterogeneity was present according to $\chi^{2}(P<0.001)$. One of the trials ${ }^{27,37}$ reported body max index (BMI) instead of weight. In order to include this outcome with the rest of the studies, participants' BMIs were transformed to kilograms assuming that

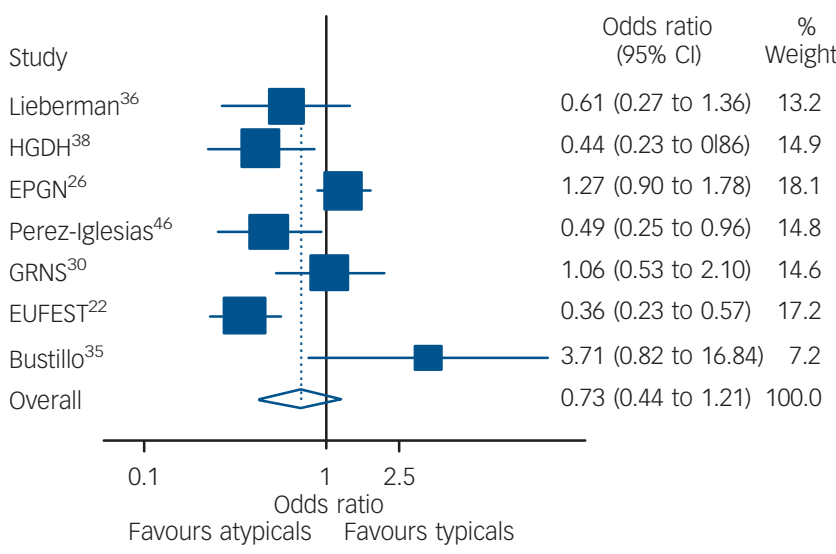

Fig. 2 Comparison of discontinuation rates among participants receiving first- $v$. second-generation antipsychotics.

$P=0.22$. Heterogeneity $\chi^{2}=28.55$ (d.f. =6) $P<0.001, I^{2}=79.0 \%$. EPGN, Early Psychosis Global Network; GRNS, German Research Network on Schizophrenia; EUFEST European First-Episode Schizophrenia Trial.

For clarity purposes, the first author of the first published paper is used in Table DS1 in cases where more than one article reporting outcomes of the study has been included. everyone's height was $1.70 \mathrm{~m}$ (an assumption that probably decreased its variance). Excluding this study from the analysis had little effect on the results and only marginally decreased heterogeneity ( $I^{2}$ decreased from 80 to $74 \%$ ). Meta-regressions were performed using the following covariates: amount of time exposed, typical doses, and percentage of participants receiving olanzapine or clozapine. None of these factors reached statistical significance.

For an analysis of extrapyramidal side-effects, nine studies with 1341 participants were pooled. As described previously, most of the studies utilised the high-potency antipsychotic haloperidol and only two used zuclopenthixol and chlorpromazine. Rating scales reported varied, with five studies using the Simpson-Angus Scale (SAS), ${ }^{13,28,30,36,38}$ three studies the Extrapyramidal Symptom Rating Scale (ESRS), ${ }^{24,26,39}$ and one the St Hans Rating Scale for Extrapyramidal Syndrome (SHRS). ${ }^{22}$ There are differences between the rating scales, but all of them include an objective evaluation of parkinsonism. The SHRS and ESRS both rate dystonia and akathisia, and the latter also includes a

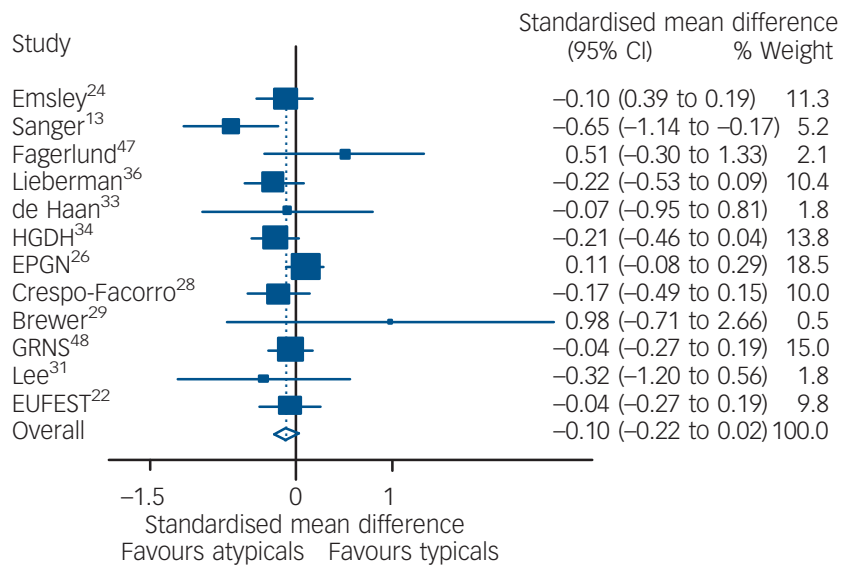

Fig. 3 Comparisons of symptoms scales at short term (around 3 months) between the two groups.

Effect sizes were standardised using Hedges' $g$ and pooled using a random-effects model. Non-significant difference favouring atypicals shown $(P=0.12)$. Heterogeneity $\chi^{2}=15.3$ (d.f. $\left.=11\right) P=0.17, I^{2}=28 \%$. EPGN, Early Psychosis Global Network; GRNS, German Research Network on Schizophrenia; EUFEST, European First-Episode Schizophrenia Trial.

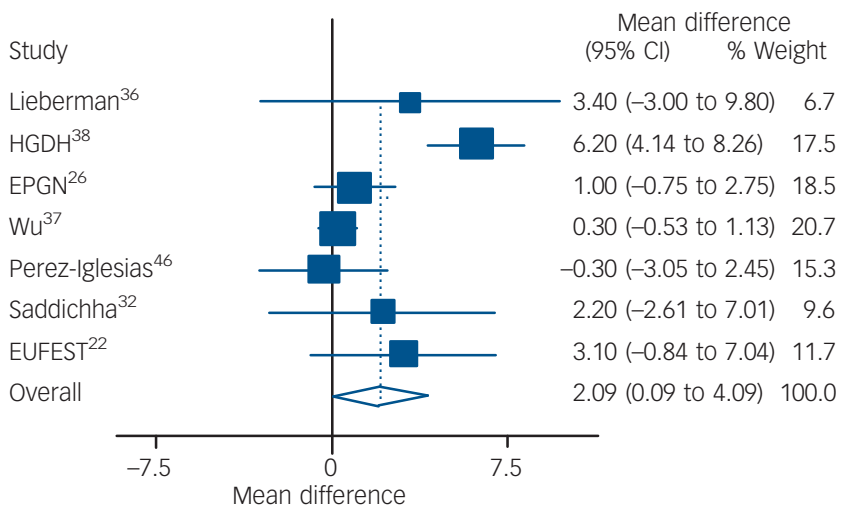

Increase weight in typicals Increase weight in atypicals

Fig. 4 Comparison of weight gain between the two groups.

Data expressed in kilograms, and pooled using random-effects model. Significant weight gain found in atypical group $(P=0.04)$. Heterogeneity $\chi^{2}=29.79$ (d.f. $=6$ ) $P<0.001, I^{2}=79.9 \%$. EPGN, Early Psychosis Global Network; GRNS, German Research Network on Schizophrenia; EUFEST, European First-Episode Schizophrenia Trial. 


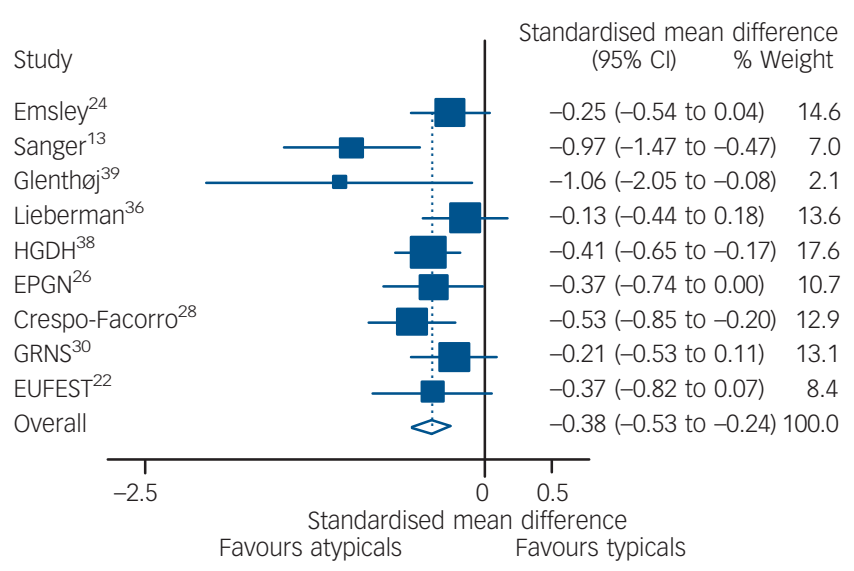

Fig. 5 Extrapyramidal side-effects in both groups using standardised mean differences.

A highly significant difference favouring atypicals was found $(P<0.001)$. Note that all individual trials favour atypicals. Heterogeneity $\chi^{2}=12.3($ d.f. $=8) P=0.14, I^{2}=35 \%$. EPGN, Early Psychosis Global Network; GRNS, German Research Network on Schizophrenia; EUFEST, European First-Episode Schizophrenia Trial.

questionnaire to assess the subjective experience of extrapyramidal signs. In order to make these different scales comparable, only parkinsonism scores were extracted from these two scales when possible, and effect sizes were standardised. This was not possible in one study which reported global ESRS ${ }^{39}$ and in another one in which we used total ESRS at end-point (24 months) of observed cases provided by one of the authors. ${ }^{26}$ We repeated this analysis excluding them. It should be noted that the results of this analysis apply to parkinsonism and not necessarily to other extrapyramidal symptoms such as akathisia. We found a significant advantage of atypicals over typicals as shown in Fig. 5 (s.d. $=-0.38$ favouring atypicals, $P<0.001)$. Heterogeneity using chi-squared was not statistically significant $(P=0.14)$, and a fixed-effects analysis left the results substantially unchanged (s.d. $=-0.37,95 \%$ CI -0.48 to -0.25 ). Meta-regression analyses looking at dose of typical antipsychotics, amount of time exposed, and proportion of individuals receiving risperidone or amisulpride did not produce any statistically significant results. Exclusion of the two studies from which global ESRS scores were used did not substantially change the results.

\section{Discussion}

\section{Main findings}

We did not find a significant difference between atypical and typical antipsychotics in discontinuation rates. Discontinuation seems an appealing concept reflecting both efficacy of a drug and side-effects, but unfortunately there does not appear to be a consensus defining what exactly discontinuing a drug is: definitions of discontinuation ranged from irregularities in the adherence to a medication regime (e.g., taking lower doses of the assigned antipsychotic than prescribed for a period of 2 weeks as in Kahn et al) ${ }^{22}$ to total discontinuation of the study drug (as in Schooler et al) ${ }^{26}$ in the studies included in this meta-analysis. It is possible that a number of factors underpin these variations in what is defined as 'discontinuation' and this could be one of the causes of the significant statistical heterogeneity present in that comparison. Since only one study explicitly defined discontinuation in the context of being the primary outcome, ${ }^{22}$ we were not able to analyse whether variation in the definition of discontinuation had an effect on the pooled outcome.
We found no significant difference between atypical and typical antipsychotics in acute symptomatic effect. Individuals with first-episode psychosis usually show a good symptomatic response to antipsychotic treatment, ${ }^{11}$ and this may have introduced a ceiling effect that complicated comparisons. However, even if additional studies had been included such that the power of the analysis was increased, the estimated effect size of s.d. $=0.1$ (equivalent to two points on the PANSS scale using the variance found in the biggest study included $)^{26}$ suggests that even if a significant difference could be identified it may not be clinically meaningful. A previously published study found that a one-step change in the Clinical Global Improvement scale (allegedly a more 'clinically meaningful' scale) required a 15-point change on the PANSS. ${ }^{40} \mathrm{~A}$ meta-analysis of treatment in chronic schizophrenia found an advantage for atypicals only when compared with high doses of typicals. ${ }^{1}$ In the present study, although the doses of typical antipsychotics prescribed in the studies we analysed were low, there was a similar trend for atypicals to be superior when the comparison involved higher doses of typicals. Although this observation was not significant, it supports the notion that when using typical antipsychotics in individuals with a first episode, lower doses of medication are indicated compared with individuals with chronic schizophrenia.

Although there were no significant differences between atypicals and typicals in discontinuation rates or symptom control, we did find differences in their side-effect profile. In line with previous studies ${ }^{41,42}$ our meta-analysis found that, on average, participants prescribed an atypical antipsychotic would gain $2 \mathrm{~kg}$ more than those on typicals, whereas those prescribed a typical antipsychotic would rate 0.4 standard deviations higher in the extrapyramidal scales (e.g. approximately one extra point in the SAS if using the data from one of the studies included) ${ }^{28}$ We did not find a correlation between these findings and the use of specific atypical drugs that have been particularly associated with weight gain or extrapyramidal side-effects. This does not mean we can exclude any differences between the atypicals in their side-effect profiles in first-episode participants as this meta-analysis was not designed to look at within-class differences, and our meta-regression analysis was probably underpowered. As most of the studies we analysed included haloperidol, there is a possibility that the difference in extrapyramidal side-effects between atypicals and low-potency typical antipsychotics is less marked, as is the case in people with chronic schizophrenia. $^{2}$

\section{Future research}

This meta-analysis leaves many questions unanswered. First, it would have been interesting to look at differences in relapse rates between atypicals and typicals. We decided not to pool this outcome as there were too few studies reporting it. From the long-term studies included in this meta-analysis, three reported relapse rates in participants who achieved remission ${ }^{26,30,38}$ and one reported readmissions to hospital in participants recruited from an in-patient unit. ${ }^{36}$ Of these four, three reported no significant differences. ${ }^{30,36,38}$ The other trial, ${ }^{26}$ which was the largest and longest, reported significantly lower relapse rates with risperidone compared with haloperidol $(42.1 \%$ v. $54.7 \%$ respectively), even though no differences were found in remission and medication adherence. As relapse is an important determinant of long-term outcome, this should be a serious consideration in the choice of antipsychotic. Further large long-term studies would be needed to verify this study's findings. Second, some of the most important risks with antipsychotics such as diabetes (seen with some atypicals) or tardive dyskinesia (commonly seen with 
typicals) usually appear after years of exposure to these medications. This makes it exceedingly unlikely that this will ever be studied using randomised controlled trials. However, these serious long-term outcomes should also be considered when deciding upon maintenance medication. Changes in glucose and lipid blood levels with antipsychotic medication could be seen as an intermediate outcome in metabolic complications, but the small proportion of studies reporting this outcome from the included studies discouraged us to perform a meta-analysis.

Recent criticisms have been raised about the validity of atypical antipsychotics as a group. ${ }^{43,44}$ This is backed mostly by two recent meta-analyses by Leucht et al, who reported differences within the atypical antipsychotics ${ }^{45}$ and also when compared with typical antipsychotics. ${ }^{4}$ As already mentioned, our meta-analysis was not designed to look at differences within the atypical antipsychotics. Nevertheless, it should be noted that almost all the drugs included in this meta-analysis were those that were reported as more effective than their comparisons for chronic schizophrenia in the above mentioned studies (namely olanzapine, risperidone, clozapine and amisulpride).

\section{Implications}

This meta-analysis revealed no significant differences between typical and atypical antipsychotics in discontinuation rates or in short-term symptomatic response in individuals with first-episode psychosis. However, treatment with atypical antipsychotics was associated with relatively more weight gain, whereas treatment with typicals was associated with a greater incidence of extrapyramidal side-effects. Choice of antipsychotic drug in the treatment of first-episode psychosis may thus be more influenced by side-effect profile than efficacy.

Nicolas A. Crossley, MRCPsych, MSC, Miguel Constante, MRCPsych, Division of Psychological Medicine, Institute of Psychiatry, London; Philip McGuire, FRCPsych, PhD, Division of Psychological Medicine, Institute of Psychiatry, and Outreach and Support in South London (OASIS), South London and Maudsley NHS Foundation Trust, London; Paddy Power, MRCPsych, FRANZCP, MD, Division of Psychological Medicine, Institute of Psychiatry, and Lambeth Early Onset Services (LEO), South London and Maudsley NHS Foundation Trust, London, UK

Correspondence: Nicolas A. Crossley, Division of Psychological Medicine Institute of Psychiatry PO 67, De Crespigny Park, London SE5 8AF. Email: nicolas.crossley@kcl.ac.uk

First received 17 Mar 2009, final revision 2 Dec 2009, accepted 17 Feb 2010

\section{Funding}

N.A.C. is in receipt of an Academic Training Fellowship from the National Institute of Health Research, UK.

\section{Acknowledgements}

We are grateful to Dr Han Boter, Dr Warrick Brewer, Dr Juan Bustillo, Professor Robin Emsley, Professor Wolfgang Gaebel, Dr Ragy Girgis, Dr Birte Glenthøj, Professor Rene Kahn, Mr Keith Karcher, Professor Jeffrey Lieberman, Professor Jonathan Rabinowitz and Dr Mathias Riesbeck who provided unpublished data to the authors and clarified all the doubts we had. We would also like to thank Dr Daniel Stahl for statistical advice.

\section{References}

1 Geddes J, Freemantle N, Harrison P, Bebbington P. Atypical antipsychotics in the treatment of schizophrenia: systematic overview and meta-regression analysis. BMJ 2000; 321: 1371-6.

2 Leucht S, Wahlbeck K, Hamann J, Kissling W. New generation antipsychotics versus low-potency conventional antipsychotics: a systematic review and meta-analysis. Lancet 2003; 361: 1581-9.

3 Davis JM, Chen N, Glick ID. A meta-analysis of the efficacy of secondgeneration antipsychotics. Arch Gen Psychiatry 2003; 60: 553-64.
4 Leucht S, Corves C, Arbter D, Engel RR, Li C, Davis JM. Second-generation versus first-generation antipsychotic drugs for schizophrenia: a metaanalysis. Lancet 2009; 373: 31-41.

5 Lieberman JA, Stroup TS, McEvoy JP, Swartz MS, Rosenheck RA, Perkins DO, et al; Clinical Antipsychotic Trials of Intervention Effectiveness (CATIE) Investigators. Effectiveness of antipsychotic drugs in patients with chronic schizophrenia. N Engl J Med 2005; 353: 1209-23.

6 Jones PB, Barnes TR, Davies L, Dunn G, Lloyd H, Hayhurst KP, et al. Randomized controlled trial of the effect on Quality of Life of second- vs firstgeneration antipsychotic drugs in schizophrenia: Cost Utility of the Latest Antipsychotic Drugs in Schizophrenia Study (CUtLASS 1). Arch Gen Psychiatry 2006; 63: 1079-87.

7 Rosenheck RA, Leslie DL, Sindelar J, Miller EA, Lin H, Stroup TS, et al; CATIE Study Investigators. Cost-effectiveness of second-generation antipsychotics and perphenazine in a randomized trial of treatment for chronic schizophrenia. Am J Psychiatry 2006; 163: 2080-9.

8 Davies LM, Lewis S, Jones PB, Barnes TRE, Gaughran F, Hayhurst K, et al; CUtLASS team. Cost-effectiveness of first- $v$. second-generation antipsychotic drugs: results from a randomised controlled trial in schizophrenia responding poorly to previous therapy. Br J Psychiatry 2007; 191: 14-22.

9 Large M, Farooq S, Nielssen O, Slade T. Relationship between gross domestic product and duration of untreated psychosis in low- and middle-income countries. Br J Psychiatry 2008; 193: 272-8.

10 Lewis S, Lieberman J. CATIE and CUtLASS: can we handle the truth? Br J Psychiatry 2008; 192: 161-3

11 Robinson DG, Woerner MG, Alvir JM, Geisler S, Koreen A, Sheitman B, et al. Predictors of treatment response from a first episode of schizophrenia or schizoaffective disorder. Am J Psychiatry 1999; 156: 544-9.

12 Oosthuizen $\mathrm{P}$, Emsley R, Jadri Turner $\mathrm{H}$, Keyter N. A randomized, controlled comparison of the efficacy and tolerability of low and high doses of haloperidol in the treatment of first-episode psychosis. Int J Neuropsychopharmacol 2004; 7: 125-31.

13 Sanger TM, Lieberman JA, Tohen M, Grundy S, Beasley Jr C, Tollefson GD. Olanzapine versus haloperidol treatment in first-episode psychosis. Am J Psychiatry 1999; 156: 79-87.

14 Smith M, Hopkins D, Peveler RC, Holt RIG, Woodward M, Ismail K. First- $v$. second-generation antipsychotics and risk for diabetes in schizophrenia: systematic review and meta-analysis. Br J Psychiatry 2008; 192: 406-11.

15 Cotton SM, Lambert M, Schimmelmann BG, Foley DL, Morley KI, McGorry PD, Conus P. Gender differences in premorbid, entry, treatment, and outcome characteristics in a treated epidemiological sample of 661 patients with first episode psychosis. Schizophr Res 2009; 114: 17-24.

16 Rummel C, Hamann J, Kissling W, Leucht S. New generation antipsychotics for first episode schizophrenia. Cochrane Database Syst Rev 2003; 4 CD004410.

17 National Institute for Health and Clinical Excellence. Schizophrenia. NICE Clinical Guideline 82. NICE, 2009 (http://www.nice.org.uk/nicemedia/pdf/ CG82NICEGuideline.pdf).

18 Emsley R, Rabinowitz J, Medori R. Time course for antipsychotic treatment response in first-episode schizophrenia. Am J Psychiatry 2006; 163: 743-5.

19 Robinson DG, Woerner MG, Delman HM, Kane JM. Pharmacological treatments for first-episode schizophrenia. Schizophr Bull 2005; 31 : 705-22.

20 DerSimonian R, Laird N. Meta-analysis in clinical trials. Control Clin Trials 1986; 7: 177-88

21 Egger M, Davey Smith G. Systematic Reviews in Health Care: Meta-analysis in Context (2nd edn). BMJ Publishing Group, 2001.

22 Kahn RS, Fleischhacker WW, Boter H, Davidson M, Vergouwe Y, Keet IP, et al; EUFEST study group. Effectiveness of antipsychotic drugs in first-episode schizophrenia and schizophreniform disorder: an open randomised clinical trial. Lancet 2008; 371: 1085-97.

23 Egger M, Davey Smith G, Schneider M, Minder C. Bias in meta-analysis detected by a simple, graphical test. BMJ 1997; 315: 629-34.

24 Emsley RA. Risperidone in the treatment of first-episode psychotic patients: a double-blind multicenter study. Risperidone Working Group. Schizophr Bull 1999; 25: 721-9.

25 Mackeprang T, Kristiansen KT, Glenthøj BY. Effects of antipsychotics on prepulse inhibition of the startle response in drug-naïve schizophrenic patients. Biol Psychiatry 2002; 52: 863-73.

26 Schooler N, Rabinowitz J, Davidson M, Emsley R, Harvey PD, Kopala L, et al; Early Psychosis Global Working Group. Risperidone and haloperidol in firstepisode psychosis: a long-term randomized trial. Am J Psychiatry 2005; 162: 947-53. 
27 Wu RR, Zhao JP, Liu ZN, Zhai JG, Guo XF, Guo WB, et al. Effects of typical and atypical antipsychotics on glucose-insulin homeostasis and lipid metabolism in first-episode schizophrenia. Psychopharmacology (Berl) 2006; 186: 572-8.

28 Crespo-Facorro B, Pérez-Iglesias R, Ramirez-Bonilla M, Martínez-García O, Llorca J, Luis Vázquez-Barquero J. A practical clinical trial comparing haloperidol, risperidone, and olanzapine for the acute treatment of firstepisode nonaffective psychosis. J Clin Psychiatry 2006; 67: 1511-21.

29. Brewer WJ, Yücel M, Harrison BJ, McGorry PD, Olver J, Egan GF, et al. Increased prefrontal cerebral blood flow in first-episode schizophrenia following treatment: Iongitudinal positron emission tomography study. Aust N Z J Psychiatry 2007; 41: 129-35.

30 Gaebel W, Riesbeck M, Wölwer W, Klimke A, Eickhoff M, von Wilmsdorff M, et al; German Study Group on First-Episode Schizophrenia. Maintenance treatment with risperidone or low-dose haloperidol in first-episode schizophrenia: 1-year results of a randomized controlled trial within the German Research Network on Schizophrenia. J Clin Psychiatry 2007; 68: 1763-74.

31 Lee SM, Chou YH, Li MH, Wan FJ, Yen MH. Effects of antipsychotics on cognitive performance in drug-naive schizophrenic patients. Prog Neuropsychopharmacol Biol Psychiatry 2007; 31: 1101-7.

32 Saddichha S, Manjunatha N, Ameen S, Akhtar S.Diabetes and schizophrenia effect of disease or drug? Results from a randomized, double-blind, controlled prospective study in first-episode schizophrenia. Acta Psychiatr Scand 2008; 117: 342-7.

33 de Haan L, van Bruggen M, Lavalaye J, Booij J, Dingemans PM, Linszen D. Subjective experience and D2 receptor occupancy in patients with recentonset schizophrenia treated with low-dose olanzapine or haloperidol: a randomized, double-blind study. Am J Psychiatry 2003; 160: 303-9.

34 Lieberman JA, Tollefson G, Tohen M, Green Al, Gur RE, Kahn R, et al; HGDH Study Group. Comparative efficacy and safety of atypical and conventional antipsychotic drugs in first-episode psychosis: a randomized, double-blind trial of olanzapine versus haloperidol. Am J Psychiatry 2003; 160: 1396-404

35 Bustillo JR, Rowland LM, Jung R, Brooks WM, Qualls C, Hammond R, et al. Proton Magnetic Resonance Spectroscopy During Initial Treatment With Antipsychotic Medication in Schizophrenia. Neuropsychopharmacology 2008 33: 2456-66.

36 Lieberman JA, Phillips M, Gu H, Stroup S, Zhang P, Kong L, et al. Atypical and conventional antipsychotic drugs in treatment-naive first-episode schizophrenia: a 52-week randomized trial of clozapine vs chlorpromazine. Neuropsychopharmacology 2003; 28: 995-1003.

37 Wu RR, Zhao JP, Zhai JG, Guo XF, Guo WB. Sex difference in effects of typical and atypical antipsychotics on glucose-insulin homeostasis and lipid metabolism in first-episode schizophrenia. J Clin Psychopharmacol 2007; 27: $374-9$.

38 Green Al, Lieberman JA, Hamer RM, Glick ID, Gur RE, Kahn RS, et al; HGDH Study Group. Olanzapine and haloperidol in first episode psychosis: two-year data. Schizophr Res 2006; 86: 234-43.

39 Glenthøj A, Glenthøj BY, Mackeprang T, Pagsberg AK, Hemmingsen RP, Jernigan $\mathrm{TL}$, et al. Basal ganglia volumes in drug-naive first-episode schizophrenia patients before and after short-term treatment with either a typical or an atypical antipsychotic drug. Psychiatry Res 2007; 154: 199-208.

40 Leucht S, Kane JM, Etschel E, Kissling W, Hamann J, Engel RR. Linking the PANSS, BPRS, and CGI: clinical implications. Neuropsychopharmacology 2006; 31: 2318-25.

41 Alvarez-Jiménez M, González-Blanch C, Crespo-Facorro B, Hetrick S, Rodríguez-Sánchez JM, Pérez-lglesias R, et al. Antipsychotic-induced weight gain in chronic and first-episode psychotic disorders: a systematic critical reappraisal. CNS Drugs 2008; 22: 547-62.

42 Park S, Ross-Degnan D, Adams AS, Sabin J, Kanavos P, Soumerai SB. Effect of switching antipsychotics on antiparkinsonian medication use in schizophrenia: population-based study. Br J Psychiatry 2005; 187: 137-42.

43 Tyrer $P$, Kendall $T$. The spurious advance of antipsychotic drug therapy. Lancet 2009; 373: 4-5.

44 Margolis RL. Neuropsychiatric disorders: the choice of antipsychotics in schizophrenia. Nat Rev Neurol 2009; 5: 308-310.

45 Leucht S, Komossa K, Rummel-Kluge C, Corves C, Hunger H, Schmid F, et al. A meta-analysis of head-to-head comparisons of second-generation antipsychotics in the treatment of schizophrenia. Am J Psychiatry 2009; 166 $152-63$.

46 Perez-Iglesias R, Crespo-Facorro B, Martinez-Garcia O, Ramirez-Bonilla ML, Alvarez-Jimenez $M$, Pelayo-Teran JM, et al. Weight gain induced by haloperidol, risperidone and olanzapine after 1 year: findings of a randomized clinical trial in a drug-naïve population. Schizophr Res 2008; 99: 13-22.

47 Fagerlund B, Mackeprang T, Gade A, Glenthøj BY. Effects of low-dose risperidone and low-dose zuclopenthixol on cognitive functions in firstepisode drug-naive schizophrenic patients. CNS Spectr 2004; 9: 364-74.

48 Möller HJ, Riedel M, Jäger M, Wickelmaier F, Maier W, Kühn KU, et al. Short-term treatment with risperidone or haloperidol in first-episode schizophrenia: 8-week results of a randomized controlled trial within the German Research Network on Schizophrenia. Int J Neuropsychopharmacol 2008; 11: 985-7

\section{On therapy}

\section{Ramy Daoud}

I worked in medicine for many years before I was drawn to psychiatry. My encounters with patients with physical ailments prefigured those encounters I would have as a psychiatrist. The cognition of pain. The search for meaning. The elicitation of a story. The laying of hands on where it hurts. The re-cognition of pain. Sometimes I would cut it out. Sometimes I would cover it up. Sometimes I could do neither. In these instances, I am reminded of Mural by the Palestinian poet of exile, Darwish. I find it quite a haunting piece, lingering in the back of my mind before, during, between sessions with patients. A patient knocks at the door of therapy. Therapy: 'the dialogue of dreamers' where the patient 'shuns body and self . . . to finish that first journey towards meaning, which burnt me, and disappeared.' Disappeared into absence and no space, where 'nothing hurts at the door of doom'. In no space, and no time, that insistent voice says 'one day I shall become.... And they come, knocking at the door of therapy. Therapy is a space-time, an en-closure where dis-closure unfolds through language/thoughts ('one day I shall become a thought'), that threatens to 'split [the patient's nascent sense of being like] a burgeoning blade of grass'. A battle-field, between 'neither being nor nothingness'. Therapy, language, the act of re-telling one's story seems to me like a sword 'wresting being from non-being', that promises an 'epiphany'. That epiphany that comes on the wings of the words: 'This is your name'. Darwish's 'epiphany' reminds me of Heidegger's Da-sein and the ecstasy of temporality. Being which temporalises itself yet unites past, present and future 'selves'. I believe Darwish wishes to leave this activity of being open: 'I know this epiphany, and know I'm on my way towards what I don't know'.

Ramy Daoud is specialty registrar in general adult psychiatry, East Cornwall Community Mental Health Team. 